\title{
Biolistic-mediated plasmid-free transformation for induction of hairy roots in tobacco plants
}

\author{
Gulnar Yasybaeva, Zilya Vershinina, Bulat Kuluev, Elena Mikhaylova, Andrey Baymiev \\ and Aleksey Chemeris
}

Institute of Biochemistry and Genetics, Ufa Scientific Centre, Russian Academy of Sciences (IBG USC RAS), pr. Oktyabrya 71, 450054, Ufa, Russia

Corresponding author. G. Yasybaeva, E-mail: gulnar.yas@mail.ru, Phone: +7-937-480-9956

Received on December 13, 2016; Accepted on March 8, 2017

\begin{abstract}
T-DNA of Ri-plasmid from Agrobacterium rhizogenes is able to trigger the hairy root syndrome in infected plants. This natural phenomenon is used to generate hairy root cultures predominantly only in dicotyledonous plants. We propose a new method of hairy roots induction without Agrobacterium-mediated transformation. The $5461 \mathrm{bp}$ T-DNA region from $A$. rhizogenes A4 strain with all four $r o l$ genes was amplified using primers containing sequences for left and right T-DNA borders on their 3'-ends. This amplicon was used for direct transformation of tobacco leaf discs without $A$. rhizogenes and binary vectors. We showed the possibility of generation of hairy roots on tobacco leaf discs by biolistic transformation utilizing only rol genes amplicon.
\end{abstract}

Keywords: Agrobacterium rhizogenes, hairy roots, rol genes, biolistic transformation, transgenic plants, Nicotiana tabacum

\begin{abstract}
Abbreviations: $R i$-plasmid, root induce plasmid; rol-genes, root locus genes; T-DNA, transfer DNA; HRC, hairy roots culture
\end{abstract}

\section{Introduction}

The gram-negative soil bacterium Agrobacterium rhizogenes (Rhizobium rhizogenes) cause neoplastic and plagiotropic growth of hairy roots for various dicotyledons. This microorganism carries a $R i$ plasmid with T-DNA containing rol genes (rolA, rolB, rolC and rolD), which are able to integrate into the plant genome. The rol genes expression disturbs the normal functioning of the plant (in particular, affects the hormonal balance), which leads to certain morphological changes of the transformed plant tissue, specifically, promotes the appearance of hairy roots. Hairy roots culture (HRC) can be used for production of various secondary metabolites such as alkaloids, terpenoids, phenols, glycosides (Sharifi et al. 2014). Some of them are a source of pharmaceutical raw materials or other economically valuable compounds. HRCs also can be used as recombinant proteins producers (Ono and Tian 2011).

In natural conditions soil bacteria $A$. rhizogenes infects healthy plants by penetrating through injured roots. Thereby simple way of making hairy roots is co-cultivation of plant explants wounded by a scalpel or a needle with Agrobacterium suspension in vitro (Van de Velde et al. 2003). Another commonly used technique is wounding of plant tissue in vivo by injection of Agrobacterium suspension (Kereszt et al. 2007, Estrada-Navarrete et al. 2007). Previously a different approach of hairy roots formation through single rol gene or rol genes combination was proposed (Spena et al. 1987, Cardarelli et al. 1987, Vilaine and Casse-Delbart 1987). These rol genes were cloned in binary vectors and were used to transform Agrobacterium tumefaciens strains (Bonhomme et al. 2000, Hong et al. 2006 etc.) which finally infected plant material; co-cultivation plant material with $A$. rhizogenes strains (Bertoli et al. 2008, Tusevski et al. 2013, Thilip et al. 2015, Rana et al. 2016 etc.); or biolistic bombardment (Aguado-Santacruz et al. 2009).

The main drawback of the previously described techniques is the high dependence of the transformation efficiency on the strain of $A$. rhizogenes and species of infected plant. For example Rhaponticum carthamoides was easier transformed by A. rhizogenes strain A4 (Skala et al. 2015); strains ATCC 13333 and ATCC 15834 were

Yasybaeva G, Vershinina Z, Kuluev B, Mikhaylova E, Baymiev A, Chemeris A 2017 Biolistic-mediated plasmid-free transformation for induction of hairy roots in tobacco plants. Plant Root 11:33-39. doi:10.3117/plantroot.11.33 
the most suitable for Capsicum frutescens, while ATCC 43056 and ATCC 43057 were the most appropriate for Capsicum annuum (Setamam et al. 2014). A. rhizogenes used in these described techniques have natural ability to induce hairy roots predominantly in dicotyledons. Therefore the attempts of hairy roots induction on gymnosperms and monocotyledons were failed except for some works (McAfee et al. 1993, Magnussen et al. 1994, Mihaljevic et al. 1996, Yibrah et al. 1995, Xu et al. 2006). Pioneer work of hairy root induction on cereals was work of Lee et al. (2001) who successfully transformed rice with a construct containing rolA under the control of a double $35 \mathrm{~S}$ promoter via polyethylene glycol mediated protoplast transformation. Also HRCs were made on cereals such as Dioscorea deltoidea which is a source of important pharmacological steroids (Avula et al. 2014) and blue grama grass (Bouteloua gracilis) in order to determine the effects associated to the expression of rol genes in a forage grass genetic context (Aguado-Santacruz et al. 2009). Moreover, many dicotyledons are not susceptible to be transformed by $A$. rhizogenes. For example, attempts of hairy roots induction on the $\beta$-carboline alkaloids-producer Tribulus terrestris L. failed (Sharifi et al. 2014).

There are a lot of recent works on hairy roots induction using plasmid constructions with rol genes and Agrobacterium-mediated method (Bertoli et al. 2008, Tusevski et al. 2013 etc). Though cloning step of all $\mathrm{rol}$ genes is very laborious by reason of large insert size. Moreover, strains of A. tumefaciens used in those works are able to transform mainly dicotyledons, because of the specific features of the interaction of the bacteria with the plant cell. This limits the use of these techniques towards some dicotyledons, monocots and gymnosperms. Thus it is necessary to develop new methods for hairy roots formation. We propose a method of plant explants transformation by biolistic bombardment using only T-DNA region without Agrobacterium-mediated transformation step and any plasmid vectors. Transformation of plant explants was performed using the PCR amplicon containing rolA, rolB, rolC and rolD genes from A. rhizogenes strain A4. Tobacco was chosen as a model plant, because it has been very convenient for the genetic transformation and regeneration of tissues and organs.

\section{Materials and Methods}

Plant materials and strains

Tobacco plants (Nicotiana tabacum L. cv. Petit Havana SR1) were used in this research. 30-day-old tobacco leaves were surface-sterilized for $1 \mathrm{~min}$ with $70 \%$ ethanol and for 15 min with sodium hypochlorite solution ( $3 \%$ active chlorine) containing $1 \mu \mathrm{L}$ of $100 \%$ Tween 20 and rinsed five times with sterile water. The sterile leaves were cut into pieces $(2 \times 2 \mathrm{~cm})$ and transferred to hormonefree MS medium ( $\mathrm{pH}$ 5.8). We used A. rhizogenes strain A4 for the amplification of the T-DNA fragment of $R i$ plasmid.

\section{Amplicon construction}

Genomic DNA was extracted from A. rhizogenes strain A4 using DNA-sorb-C kit (AmpliSens biotechnologies, Russia). $5401 \mathrm{bp}$ fragment of bacterial DNA containing rolA, rolB, rolC and rolD genes was amplified from total DNA of $A$. rhizogenes using LR Plus polymerase (Sileks, Russia) with following primers: rolall_F TCGAGATATTCCCACTAACCCCAATGA and rolall R TGTCCGGCAAGGTCGTCGTGCTCGTC. We performed reamplification using forward and reverse primers rolall-TL_F tggggtggcaggatatattgtggt gtaaac-TCGAGATATTCCCACTAACCCCAATGA and rolall-TR_R acgaactagacaaggggatatatcctgtca TGTCCGGCA-AGGTCGTCGTGCTCGTC to add fragments of $A$. rhizogenes T-DNA borders to the amplicon. There are small letters for nucleotides corresponding to the left and the right borders of $A$. rhizogenes T-DNA. PCR was performed in following conditions: denaturing step at $95^{\circ} \mathrm{C}$ for 4 min followed by 30 cycles of $95^{\circ} \mathrm{C}$ for $30 \mathrm{~s}$, annealing step at $57^{\circ} \mathrm{C}$ for $30 \mathrm{~s}$, extension step at $68^{\circ} \mathrm{C}$ for 8 min, and a final extension at $68^{\circ} \mathrm{C}$ for $10 \mathrm{~min}$.

The electrophoresis of the PCR products was performed on $1.0 \%$ agarose gel under a constant voltage of $80 \mathrm{~V}$. The gel was subsequently stained with ethidium bromide solution and examined under UV light.

\section{Biolistics}

Biolistic transformation was carried out with the use of Biolistic PDS-1000/He (Bio-Rad, USA). We used gold particles with an average size of 0.6 microns as microcarriers. The gold particles were coated with the amplicon containing rol genes with T-borders (1 $\mu \mathrm{g} / \mu \mathrm{L}$ ) mixed with $0.1 \mu \mathrm{M}$ spermidine and $2.5 \mathrm{M}$ $\mathrm{CaCl}_{2}$, according to Finer (Finer et al. 1992). Leaf discs were pre-incubated on MS medium with $90 \mathrm{~g} / \mathrm{L}$ sucrose for 48 hours before transformation (cultivating with increased osmotic pressure) to improve explants survival. We used the following parameters of the biolistic transformation: target distance- $6 \mathrm{~cm}$, rupture disk 450, 650 or 900 PSI, vacuum 0.9 bar, the amount of DNA per one shot- 1 $\mu \mathrm{L}(1 \mu \mathrm{g} / \mu \mathrm{L})$. Each sample of leaves (Petri plate) 
was arranged in the central half of Petri dish and received one bombardment. The whole procedures were carried out in aseptic conditions to prevent bacterial contamination in culture. After the bombardment leaf explants were transferred to hormone-free MS medium ( $\mathrm{pH}$ 5.8) for recuperation and regeneration. Petri dishes were incubated at $25^{\circ} \mathrm{C}$ under $140 \mathrm{mmol} \mathrm{m}^{-2} \mathrm{~s}^{-1}$ photon flux density and photoperiod of 16/8 hours (day/night). Roots appeared on individual leaf explants after 7-15 days of cultivation on hormone-free MS medium. We observed the beginning of de novo plant regeneration from hairy roots culture after 15-20 days of cultivation. It is known that transgenic plants expressing the rol genes have phenotype which is very distinct from the wild type. We decided to produce mature transgenic plants with rol genes as additional evidence of transformation.

\section{Genomic DNA extraction and PCR analysis}

Extraction of hairy roots genomic DNA was carried out using the cetyltrimethylammonium bromide (CTAB) method (Rogers and Bendich 1985). Once the DNA has been extracted, the polymerase chain reaction (PCR) analysis was performed to verify the presence of rol genes.

The primers were marked as rolB-F (5'-AATAAACGTTGTCGGAATGG-3') and rolB-R (5'-TAACCCCGTAGGTCTGAATA-3') to detect the rolB gene. PCR was performed according to the following protocol: denaturing step at $95^{\circ} \mathrm{C}$ for $5 \mathrm{~min}$ followed by 30 cycles of $95^{\circ} \mathrm{C}$ for $1 \mathrm{~min}$, annealing step at $53^{\circ} \mathrm{C}$ for $30 \mathrm{~s}$, extension step at $72^{\circ} \mathrm{C}$ for $50 \mathrm{~s}$, and a final extension at $72^{\circ} \mathrm{C}$ for 2 min. The 250 bp PCR product was analyzed on $1.4 \%$ of agarose gel.

\section{Results and Discussion}

The 5401 bp region was amplified from total DNA of $A$. rhizogenes strain A4 using rolall_F and rolall_ $\mathrm{R}$ primers. It was marked as amplicon A (Fig. 1A). Electrophoretic analysis showed that the amplicon A had the expected size (Fig. 1B). The sequencing of amplicon A showed that it coincides with those of the T-DNA of $A$. rhizogenes strain A4.

Using rolall-TL_F and rolall-TR_R primers, we performed reamplification and produced amplicon B (Fig. 1A) containing all rol genes, flanked on two sides with T-borders. The size of amplicon B coincided with the expected length. It was slightly longer than amplicon A (Fig. 1B). According to the sequence analysis, its both flanking regions had no nucleotide replacement.

We performed biolistic transformation of tobacco leaf disks using 5461 bp amplicon B (Fig. 1A). Putative hairy roots started to develop on leaf explants within 7-15 days after biolistic transformation (Fig. 2A, 2C). We bombarded 150 leaf explants and generated 29 putative hairy root lines. We also observed the appearance of roots in control samples that were bombarded without the addition of DNA. There were 40 leaf discs in control bombardment and one of them gave rise to roots. Accordingly we suggest that mechanical damage can lead to spontaneous root formation with a very low probability $(2.5 \%)$.

We used rupture disk with 450, 650 and 900 PSI for biolistic transformation. The highest transformation efficiency $24 \%$ was achieved when the 650 PSI rupture disk was used (Table 1). We have achieved putative transformation average efficiency in the amount of $19.3 \%$.
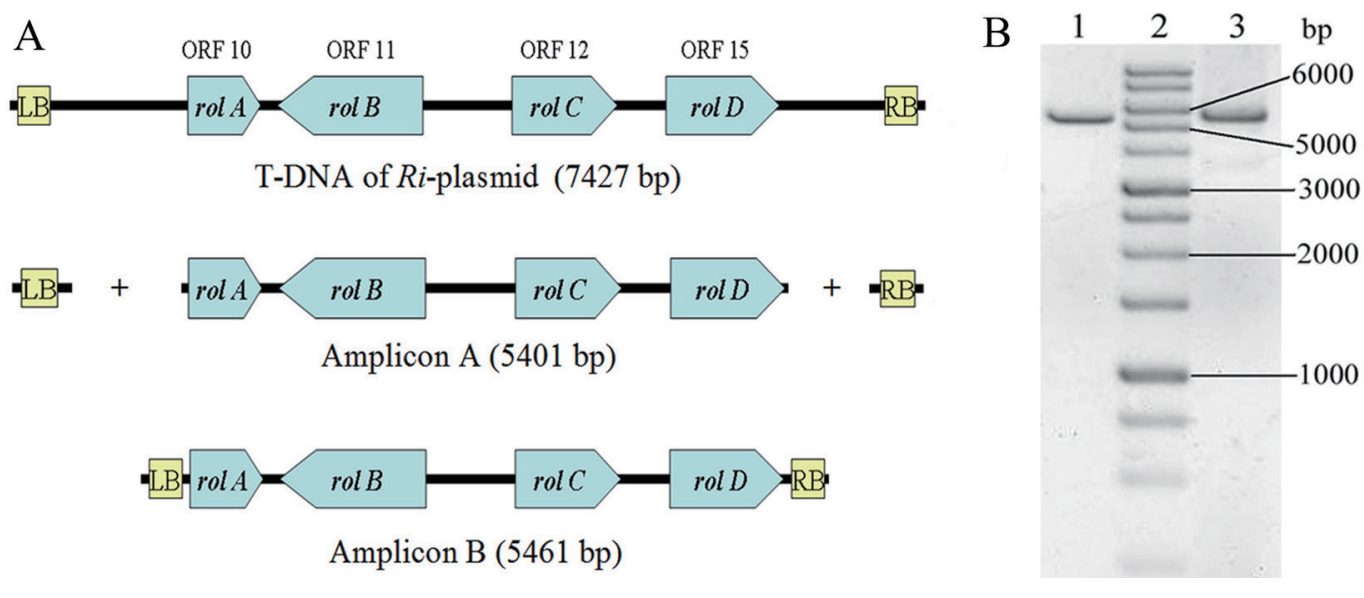

Fig. 1. PCR identification of amplicon construction. A: Schematic representation of amplicon B generating (5461 bp). Scale is not exact. B: PCR analysis of T-DNA region from total DNA of A. rhizogenes strain A4. 1: amplicon A (5401 bp); 3 amplicon B (5461 bp). 
Table 1. Optimization of biolistic conditions

\begin{tabular}{ccccc}
\hline $\begin{array}{c}\text { Rupture disk } \\
\text { selection, PSI }\end{array}$ & $\begin{array}{c}\text { Number of leaf disks, } \\
\text { pcs }\end{array}$ & $\begin{array}{c}\text { Number of produced } \\
\text { putative hairy roots, pcs }\end{array}$ & $\begin{array}{c}\text { Transformation } \\
\text { efficiency, \% }\end{array}$ & $\begin{array}{c}\text { Average transformation } \\
\text { efficiency, \% }\end{array}$ \\
\hline 450 & 50 & 10 & 20.0 & 19.3 \\
650 & 50 & 12 & 24.0 & 14.0 \\
900 & 50 & 7 & & \\
\hline
\end{tabular}
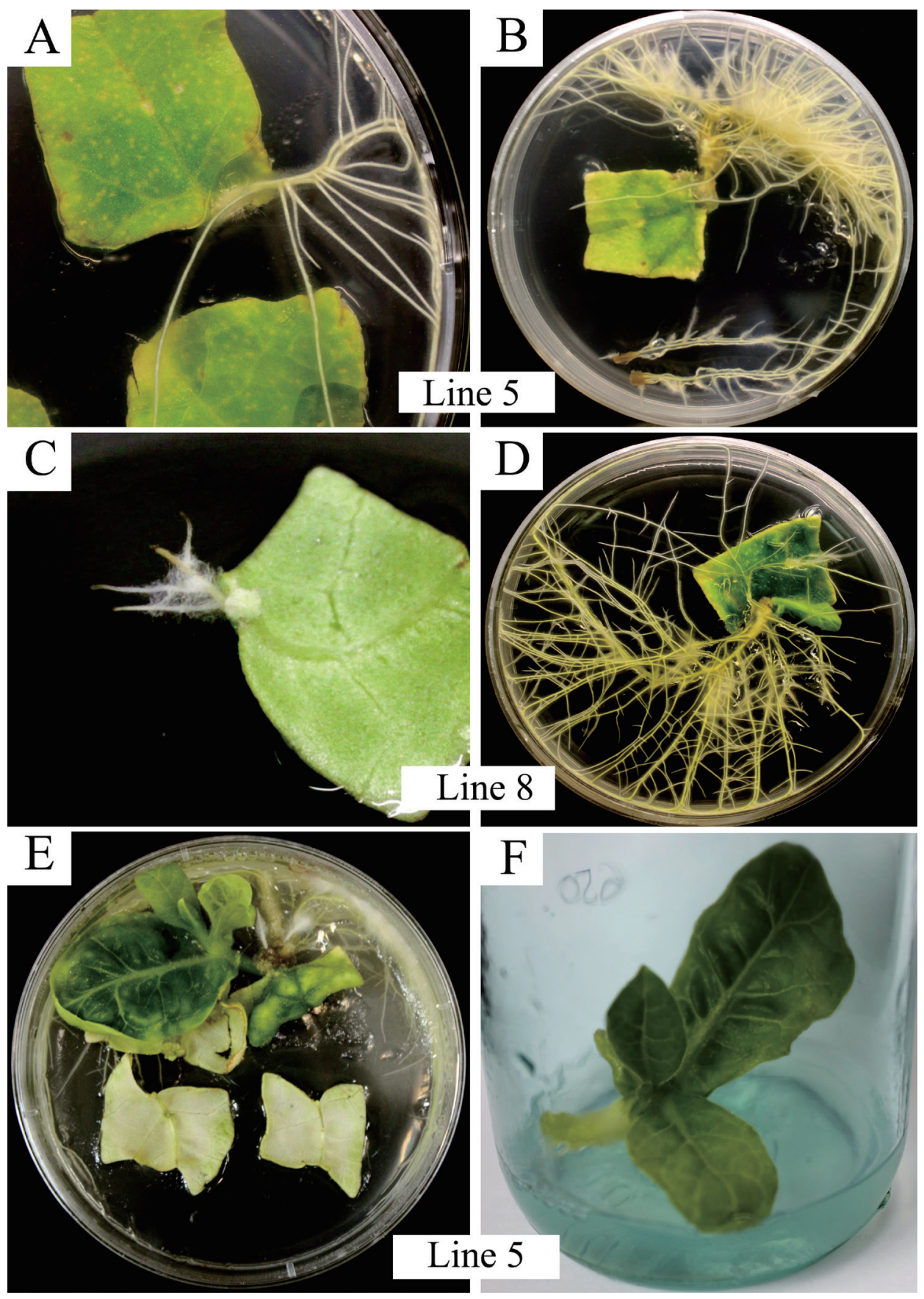

Fig. 2. Hairy roots lines 5,8 confirmed by $P C R$ analysis on the 6th day $(A, C)$ and 20th day (B, D) respectively after hairy roots appearance. Shoot regeneration on hairy roots line 5 started after 25 days (E) and 30 days (F) after bombardment. 


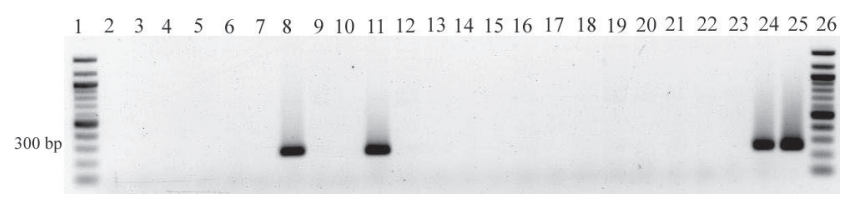

Fig. 3. PCR analysis of the hairy roots produced by particle bombardment. The $250 \mathrm{bp}$ fragments of rolB gene amplified from genomic DNA. 1, 26: marker, 2: PCR with water; 3: DNA from the intact roots (WT tobacco plants) as a negative control; 4-23: DNA from putative hairy roots; 24: template DNA from Nicotiana tabacum hairy roots as a positive control; 25: template DNA from A. rhizogenes.

To confirm the presence of rol genes in the DNA we performed PCR analysis (Fig. 3) using primers for the fragment of $r o l B$ gene because this gene is crucial for hairy root development (Nilsson and Olsson 1997). Only 20 root lines were analyzed for the presence of rolB gene because the other 9 stopped or slowed its growth within the first week, and it's unlikely that they were hairy roots. Two lines containing the $\mathrm{rolB}$ gene were found among 20 putative hairy root lines (Fig. 3). These results support that 2 tested roots had rolB gene which also proves they were truly hairy roots. We suggested that roots of the remaining 18 lines were formed as a result of transient expression of $\mathrm{rol}$ genes without stable integration of T-DNA into the plant genome. Our suggestions relate to the fact that the roots were formed with a very low probability after empty gold particles bombardment of leaf explants. Root formation efficiency was increased by 7 times when the DNA is added during bombardment of leaf explants. PCR analysis showed that these 18 root lines also did not contain rolA and rolC genes (data not shown).

The two lines, confirmed to be hairy roots, had typical phenotype, in particular, active development of branch roots and fast agravitropic growth (Fig. 2B, 2D). These roots grew faster than regular and a great diversity had been observed in the growth rate of two hairy root lines. Such a variety of growth rate probably occur due to the number of rol genes copies and their location in the plant genome (see review Altpeter et al. 2005).

We also produced tobacco roots by $10^{-5}$ M IAA (indole acetic acid) treatment of leaf explants. In the early stages of in vitro development, these auxininduced roots were phenotypically similar to hairy roots. In particular, they also demonstrated active development of branch roots and fast growth during first 2 weeks in culture, but no longer. The roots were formed during bombardment of leaf explants without T-DNA slowed its growth in a week. PCR analysis of the auxin-induced roots for the presence of rolB gene was negative.

It is known that transgenic plants expressing the rol genes have phenotype which is very distinct from the wild type (Terfer 1984). Such appearance of the roots can be one of the indirect evidence of insertion into the plant genome of rol genes. Based on this, we decided to regenerate transgenic tobacco shoots from the hairy roots. Shoot regeneration on hairy roots started after 15-20 days from bombardment and several transgenic shoots were formed. After they reached the length of $2 \mathrm{~cm}$ we transferred the shoots to the jars with non-hormonal MS medium. These in vitro plants were phenotypically similar to the plants naturally infected with $A$. rhizogenes and were scrubby, bushy and had dark green wrinkled leaves (Fig. 2E, 2F). In addition, shortening of the growing cycle in two times was observed.

The selected two lines of hairy roots were further transferred to liquid non-hormonal MS medium, where they also grew as productive as on solid medium, and the unlimited growth without any growth stimulators was observed during several months.

Consequently, using direct T-DNA transformation without $A$. rhizogenes inoculation, we were able to generate two lines of tobacco hairy roots. The main advantage of this technique is the absence of Agrobacterium contamination, because we used only genetic material of $A$. rhizogenes as amplicon (non plasmid vectors), and further transformation procedures were carried out exclusively without bacteria. It is particularly important for bioreactors, that there is no need to remove bacteria for further cultivation of the hairy roots. Due to the direct delivery of DNA, it will be possible to transform monocots and gymnosperms, because there are no stages of recognition and transfer of the T-DNA across the plasma membrane. Rearrangements of the transforming DNA may be a disadvantage, although segregation of individual transformants may give rise to several unique combinations of hairy roots lines. Then it will be necessary to select the most successful lines based on enzyme assay of the product of interest. Also there is widespread belief that particle bombardment generates large, multi-copy loci prone to instability and silencing, refinements of the technology to produce clean transgene loci have demonstrated clearly that this is not the case, and that particle bombardment has many advantages for 
the production of commercial transgenic plants that perform well in the field and comply with all relevant regulatory processes (Altpeter et al. 2005).

Thus, we have developed a new method of hairy roots induction without Agrobacterium-mediated transformation. Optimization and improvements of this method may be proposed for the plants that are uneasy to transform by traditional methods, for example, monocotyledons and gymnosperms.

\section{Acknowledgements}

This work was supported by the Russian Foundation for Basic Research (16-04-00902-a, 14-04-97005-r_ povolgie_a).

\section{References}

Aguado-Santacruz GA, Rascon-Cruz Q, Moreno-Gomez B, Guevara-Gonzalez RG, Guevara-Olvera L, JimenezBremont JF, Arevalo-Gallegos S, Garcia-Moya E 2009 Genetic transformation of blue grama grass with the rolA gene from Agrobacterium rhizogenes: regeneration of transgenic plants involves a "hairy embryo" stage. In Vitro Cell Dev. Biol. Plant. 45: 681-692.

Altpeter F, Baisakh N, Beachy R, Bock R, Capell T, Christou P, Daniell H, Datta K, Datta S, Dix PJ, Fauquet C, Huang N, Kohli A, Mooibroek H, Nicholson L, Nguyen TT, Nugent G, Raemakers K, Romano A, Somers DA, Stoger E, Taylor N, Visser R 2005 Particle bombardment and the genetic enhancement of crops: myths and realities. Mol. Breed. 15: 305-327.

Avula B, Wang YH, Ali Z, Smillie TJ, Khan IA 2014 Chemical fingerprint analysis and quantitative determination of steroidal compounds from Dioscorea villosa, Dioscorea species and dietary supplements using UHPLC-ELSD. Biomed. Chromatogr. 28: 281-294.

Bertoli A, Giovannini A, Ruffoni B, Guardo AD, Spinelli G, Mazzetti M, Pistelli L 2008 Bioactive constituent production in St. John's wort in vitro hairy roots. Regenerated plant lines. J. Agric. Food Chem. 56: 50785082.

Bonhomme V, Laurain-Mattar D, Lacoux J, Fliniaux M, Jacquin-Dubreuil A 2000 Tropane alkaloid production by hairy roots of Atropa belladonna obtained after transformation with Agrobacterium rhizogenes 15834 and Agrobacterium tumefaciens containing rol A, B, C genes only. J. Biotechnol. 81: 151-158.

Cardarelli M, Mariotti D, Pomponi M, Spano L, Capone I, Costantino P 1987 Agrobacterium rhizogenes T-DNA genes capable of inducing hairy root phenotype. Mol. Gen. Genet. 209: 475-480.

Estrada-Navarrete G, Alvarado-Affantranger X, Olivares JE, Guillen G, Diaz-Camino C, Campos F, Quinto C, Gresshoff PM, Sanchez F 2007 Fast, efficient and reproducible genetic transformation of Phaseolus spp. by Agrobacterium rhizogenes. Nat. Protoc. 2: 1819-1824.

Finer JJ, Vain P, Jones MW, McMullen MD 1992 Development of the particle inflow gun for DNA delivery to plant cells. Plant Cell Rep. 11: 323-328.

Hong SB, Peebles CA, Shanks JV, San KY, Gibson SI 2006 Terpenoid indole alkaloid production by Catharanthus roseus hairy roots induced by Agrobacterium tumefaciens harboring rol $A B C$ genes. Biotechnol. Bioeng. 93: 386-390.

Kereszt A, Li D, Indrasumunar A, Nguyen CD, Nontachaiyapoom S, Kinkema M, Gresshoff PM 2007 Agrobacterium rhizogenes-mediated transformation of soybean to study root biology. Nat. Protoc. 2: 948-952.

Lee S-H, Blackhall NW, Power JB, Cocking EC, Tepfer D, Davey MR 2001 Genetic and morphological transformation of rice with the rolA gene from the Ri TL-DNA of Agrobacterium rhizogenes. Plant Sci. 161: 917-925.

Magnussen D, Clapham D, Gronroos R, von Arnold S 1994 Induction of hairy and normal roots on Picea abies, Pinus sylvestris and Pinus cortorta by Agrobacterium rhizogenes. Scand. J. For. Res. 9: 46-51.

Martinez I 1997 Universal and rapid salt-extraction of high quality genomic DNA for PCR-based techniques. Nucl. Acids Res. 25: 4692-4693.

McAfee BJ, White EE, Pelcher LE, Lapp MS 1993 Root induction in pine (Pinus) and larch (Larix) spp. using Agrobacterium rhizogenes. Plant Cell Tiss. Org. 34: 53-62.

Mihaljevic S, Stipkovic S, Jelaska S 1996 Increase of root induction in Pinus nigra explants using agrobacteria. Plant Cell Rep. 15: 610-614.

Nilsson O, Olssen O 1997 Getting to the root: The role of the Agrobacterium rhizogenes rol genes in the formation of hairy roots. Physiol. Plant. 100: 463-473.

Ono NN, Tian L 2011 The multiplicity of hairy root cultures: prolific possibilities. Plant Sci. 180: 439-446.

Rana MM, Han ZX, Song DP, Liu GF, Li DX, Wan XC, Karthikeyan A, Wei S 2016 Effect of medium supplements on Agrobacterium rhizogenes mediated hairy root induction from the callus tissues of Camellia sinensis var. sinensis. Int. J. Mol. Sci. 17: 1132.

Rogers SO, Bendich AJ 1985 Extraction of DNA from milligram amounts of fresh, herbarium and mummified plant tissues. Plant Mol. Biol. 5: 69-76.

Setamam MN, Sidik JN, Rahman AZ, Che Mohd Zain CR 2014 Induction of hairy roots by various strains of Agrobacterium rhizogenes in different types of Capsicum species explants. BMC Res. Notes 30: 414.

Sharifi S, Sattari TN, Zebarjadi A, Majd A, Ghasempour H 2014 The influence of Agrobacterium rhizogenes on induction of hairy roots and $B$-carboline alkaloids production in Tribulus terrestris L. Physiol. Mol. Biol. Plants 20: 69-80.

Skała E, Kicel A, Olszewska MA, Kiss AK, Wysokinska H 2015 Establishment of hairy root cultures of Rhaponticum carthamoides (Willd.) Iljin for the production of biomass and caffeic acid derivatives. Biomed. Res. Int. 2015: 181098.

Spena A, Schmulling T, Koncz C, Schell JS 1987 Independent and synergistic activity of $\operatorname{rol} A, B$ and $C$ loci in stimulating abnormal growth in plants. EMBO J. 6: 3891-3899.

Terfer D 1984 Transformation of several species of higher 
plants by Agrobacterium rhizogenes: sexual transmission of the transformed genotype and phenotype. Cell 37: 959-967.

Thilip C, Raju CS, Varutharaju K, Aslam A, Shajahan A 2015 Improved Agrobacterium rhizogenes-mediated hairy root culture system of Withania somnifera (L.) Dunal using sonication and heat treatment. 3 Biotech 5: 949-956.

Tusevski O, Stanoeva JP, Stefova M, Kungulovski D, Pancevska NA, Sekulovski N, Panov S, Gadzovska SS 2013 Hairy roots of Hypericum perforatum L.: a promising system for xanthone production. Cent. Eur. J. Biol. 8: 1010-1022.

Van de Velde W, Karimi M, Den Herder G, Van Montagu M, Holsters M, Goormachtig S 2003 Agrobacterium rhizogenes- mediated transformation of plants. In: Jackson JF, Linskens HF, Eds., Genetic transformation of plants. Jackson \& Linskens, Berlin, Heidelberg, Germany, pp. 23-44.

Vilaine F, Casse-Delbart F 1987 A new vector derived from Agrobacterium rhizogenes plasmids: a micro-Ri plasmid and its use to construct a mini-Ri plasmid. Gene 55: 105-114.

Xu H, Zhou X, Lu J, Wang J, Wang X 2006 Hairy roots induced by Agrobacterium rhizogenes and production of regenerative plants in hairy root cultures in maize. Sci. China Ser. C: Life Sci. 49: 305-310.

Yibrah HS, Gronroos R, Lindroth A, Franzen H, Clapham D, von Arnold S 1996 Agrobacterium rhizogenes-mediated induction of adventitious rooting from Pinus contorta hypocotyls and the effect of 5-azacytidine on transgene activity. Transgenic Res. 5: 75-85.

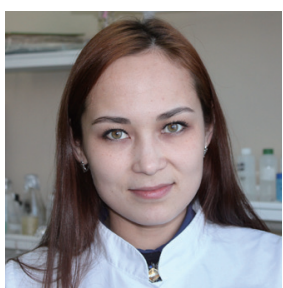

Mrs. Gulnar Yasybaeva is junior researcher in the Institute of Biochemistry and Genetics. She is interested in different methods of induction of hairy roots on various plants and molecular biology

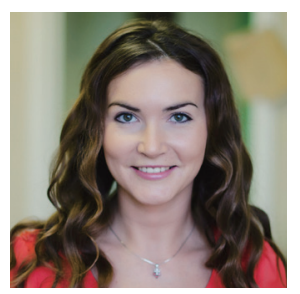

Dr. Vershinina Z.R. research interest is focused on obtaining artificial symbiotic associations between nonlegume plants and rhizobia. Her primary aim is the achievement of stable symbiotic association.

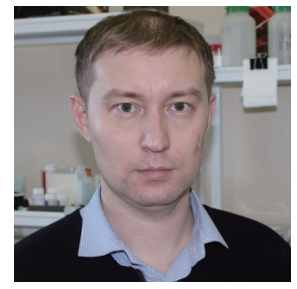

Dr. Kuluev B.R. is Senior Researcher in the Institute of Biochemistry and Genetics, Ufa Scientific Centre. Field of research - plant molecular biology, plant physiology and biochemistry, genetic engineering, biotechnology.

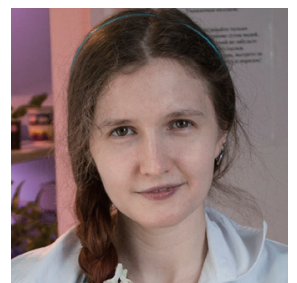

Dr. Elena Mikhaylova studies transgenic plants and their environmental safety. Her research is focused on agrobacterial transformation and cross-pollination of plants

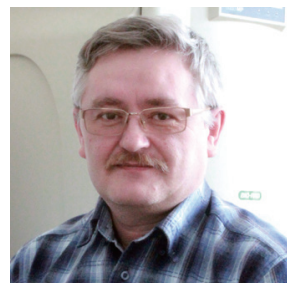

Dr. Andrei Baymiev studies genetic diversity and phylogeny of rhizobia nodulating wild-growing temperate climate bean plants. He is interested in molecular mechanisms of symbiotic nitrogen fixation

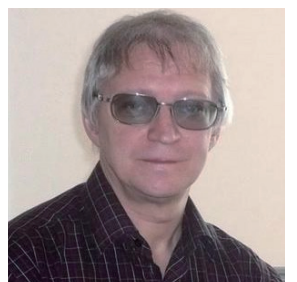

Dr. Chemeris A.V. research interest is focused on transgenic plants, biotechnology of hairy roots, NGS and genetic fingerprinting 